\title{
Correspondence
}

\section{A sore throat with a difference}

TO THE EDITOR, British fournal of Venereal Diseases SIR-Infectious mononucleosis commonly occurs in young people (Pollock, 1969) but curiously it is rarely diagnosed together with gonorrhoea in the same individual. Recently such a case was seen with a number of interesting features.

A 24-year-old white male presented on April 8, 1975, complaining of swelling of the cervical lymph nodes for 2 days and feeling generally unwell. For the previous 2 months he had had a sore throat. He admitted to active, passive, and oral sexual contact with six males over the previous 6 months.

He was afebrile and not jaundiced. There was bilateral discrete enlargement of the suboccipital, axillary, and inguinal lymph nodes but no hepatic or splenic enlargement. The throat and palate appeared normal.

Investigations showed no evidence of genital infection but culture from the tonsils showed Neisseria gonorrhoeae, identified as described by Burns, Darougar, Thin, Lothian, and Nicol (1975). Routine throat swab showed no other pathogens. The white blood count was $3,400 / \mathrm{cu}$ mm with 38 per cent. lymphocytes, 16 per cent. monocytes, and a few plasma cells. The Paul-Bunnell test gave the following results: Screening test-positive; inactivated serum titre-1/160; guinea-pig kidney absorbed titre-1/160; ox cell absorbed titre-1/40.

The patient was treated with cotrimoxazole four tablets twice daily for 2 days. The sore throat cleared and cultures from the throat on three occasions after treatment were negative for $N$. gonorrhoeae. His general condition gradually improved but it was 3 months before he was able to return to work.

Other investigations Serum Reiter protein complementfixation test, venereal disease reference laboratory test and absorbed fluorescent treponemal antibody test were negative. Liver function tests were normal. Epstein Barr (EB) virus fluorescent antibody titre on April 8 was $1: 64$, and 3 weeks' later $1: 128$. Cytomegalovirus complement-fixing antibody titre was $1: 64$ on two occasions. Rubella haemagglutination absorption test, $1: 16$. Australia antigen was negative by electrophoresis and haemagglutination.

\section{Discussion}

In the differential diagnosis of sore throat, gonorrhoea is increasing in importance (Brit. med. $\mathcal{f}$., 1974). The incidence of pharyngeal gonorrhoea is higher in females and homosexual males than in heterosexual males. Patients rarely volunteer that they have had oral contact, so they must be specifically questioned about this. Pharyngeal gonorrhoea has no characteristic clinical features (Bro-Jørgensen and Jensen, 1973) and the throat frequently looks normal. A Gram-stained smear is unhelpful because of the frequent presence of other Neisseria species. It follows that a reliable method of culture is essential for making the diagnosis. The identity of the organisms must be confirmed by their ability to ferment glucose only in a serum-free medium (Flynn and Waitkins, 1972) which was used in this case. Pharyngeal gonorrhoea may be more difficult to eradicate than anogenital gonorrhoea (Brit. med. $\mathcal{F}$., 1974), but it cleared satisfactorily in this case.

Infectious mononucleosis has an incidence in the United Kingdom of 0.2 to 0.6 per 1,000 , with a marked predilection for the age group 15 to 20 years (Pollock, 1969). It is thought to spread amongst young adults through kissing, especially when this is intimate enough to lead to transfer of saliva; in this sense infectious mononucleosis may be regarded as a sexually transmitted disease. Many patients with sexually transmitted diseases (STD) are between 18 and 20 years old, but infectious mononucleosis is rarely reported in STD patients. There are several possible reasons for this. Perhaps patients attend their general practitioners when they have systemic symptoms, sore throat, or enlarged nodes, but visit the Clinics when they suspect STD. If both sets of symptoms occur together they may conceal what they regard as irrelevant to each particular doctor.

Like other viral illnesses infectious mononucleosis may be subclinical. To detect such cases routine screening may be indicated. In this department clinically suspicious cases have been screened and only four positive PaulBunnell results have been found in the last fourteen patients. Two of the four were homosexual males.

The incubation period of mononucleosis is uncertain but probably ranges from 33 to 49 days (Pollock, 1969). There are indications that it could be 90 days or longer 
(Chang, 1975), and we have recently seen a man in this clinic who developed infectious mononucleosis 3 months after sexual contact with a woman who had the same condition. This is much longer than the incubation period of gonorrhoea when it is symptomatic (normally 2 to 5 days). If both infections are acquired at the same time, the patient will be cured of his gonorrhoea long before he develops the symptoms of infectious mononucleosis. This is the most probable explanation for the scarcity of cases of infectious mononucleosis in STD Clinics.

$$
\text { Yours faithfully, }
$$

W. A. Atia

Department of Genital Medicine,

ST. BARTHOLOMEW'S Hospital,

LONDON EC1A 7BE

May 26, 1976

\section{References}

British Medical Journal (1974) Editorial, 2, 239

BRO-JøRGENSEN, A., and JENSEN, T. (1973) Brit. F. vener. Dis., 49, 491

Burns, D. C. MACD., Darougar, S., Thin, R. N., Lothian, L., and Nicol, C. S. (1975) Ibid., 51, 314

Chang, R. S. (1975) New Engl. Y. Med., 292, 1298

FlynN, J., and Wartrins. S. A. (1972) F. clin. Path., 25, 525

Pollock, T. M. (1969) 'Infectious Mononucleosis'. Blackwell Scientific Publications, Oxford

\section{The future of venereology}

TO THE EDITOR,

British fournal of Venereal Diseases

SIR-It is unusual, but agreeable, to find myself in complete support of $\mathrm{Mr}$ Ambrose King.

'These unwise changes' have been attempted before, happily unsuccessfully, in order to alter the name of our unique and proud 'The Medical Society for the Study of Venereal Diseases'. It was Mr King's 'The' which prevailed some years ago, I think.

At that time I quoted the immortal words of a great Prime Minister, 'Why can't you let it alone'. I repeat them now, a sentiment which impinges almost hourly today, in the incessant clamour for change. 'Ours is no ordinary calling. We, whose proud boast is of the whole realm of human pathology', should preserve our classical title. Yours faithfully, W. H. Dickinson Priest 